\title{
El matriarcado gallego, el matriarcado vasco: revisión del mito en Matria de Álvaro Gago y Amama de Asier Altuna
}

\author{
Maria Boguszewicz; ; Magdalena Anna Gajewska²
}

Recibido: 18 de febreiro de 2020 / Aceptado: 29 de xuño de 2020

Resumen. En el artículo se analizan las representaciones de la mujer en dos películas que abordan el tema del matriarcado en la cultura gallega y vasca respectivamente: el cortometraje Matria de Álvaro Gago (2017) y el largometraje Amama de Asier Altuna (2015). Nuestro objetivo es reflexionar sobre cómo se construye en ellas la imagen de la mujer, qué tipos de "feminidades" reproducen, desde qué perspectiva plantean preguntas acerca del poder femenino y mediante cuáles estrategias revisan el concepto de matriarcado. La base del análisis es "el método antropológico-morfológico de obra fílmica" de Seweryn Kuśmierczyk, que parte de la premisa de que la realidad fílmica, siendo una imagen sublimada del mundo fuera de la pantalla, refleja el contexto sociocultural en que surge la película. En las conclusiones nos referimos a la ambigüedad de las interpretaciones de la condición femenina representadas en las películas analizadas. Pese a las posturas discrepantes de sus autores ante el concepto de matriarcado y a pesar de emplear lenguajes totalmente diferentes, en ambas películas se destaca su potencial para deconstruir el mito del matriarcado gallego y vasco, y para formular un comentario crítico acerca de la realidad.

Palabras clave: Galicia; País Vasco; cine; documental; mujer.

\section{[gal] O matriarcado galego, o matriarcado vasco: revisión do mito en Matria de Álvaro Gago e Amama de Asier Altuna}

Resumo. No artigo analízanse as representacións da muller en dous filmes que abordan o tema do matriarcado na cultura galega e vasca respectivamente: a curtametraxe Matria de Álvaro Gago (2017) e a longametraxe Amama de Asier Altuna (2015). O noso obxectivo é reflexionar sobre como se constrúe nelas a imaxe da muller, que tipos de "feminidades" reproducen, dende que perspectiva formulan preguntas acerca do poder feminino e mediante cales estratexias revisan o concepto de matriarcado. A base da análise é "o método antropolóxico-morfolóxico de obra fílmica" de Seweryn Kuśmierczyk, que parte da premisa de que a realidade fílmica, sendo unha imaxe sublimada do mundo fóra da pantalla, reflicte o contexto sociocultural en que xorde a película. Nas conclusións referímonos á ambigüidade das interpretacións da condición feminina representadas nas películas analizadas. A pesar das posturas discrepantes dos seus autores ante o concepto de matriarcado e pese a empregar linguaxes totalmente diferentes, ambas películas resaltan o seu potencial para deconstruír o mito do matriarcado galego e vasco, e para formular un comentario crítico acerca da realidade.

Palabras chave: Galicia; País Vasco; cinema; documental; muller.

\section{[en] Galician Matriarchy, Basque Matriarchy: Myth Revision in Álvaro Gago's Matria and Asier Altuna's Amama}

Abstract. The article analyzes the representations of the female figure in two films that poses the issue of matriarchy in, respectively, the Galician and Basque culture: the short film Matria by Álvaro Gago (2017) and the feature film Amama by Asier Altuna (2015). Our goal is to reflect on how these films construct the image of women, what types of "feminities" they reproduce, from what perspective raise questions about female power and through which strategies review the concept of matriarchy. The study is based on the "anthropological-morphological method of film analysis" by Seweryn Kuśmierczyk founded on the idea that film reality, being a sublimated image of the world outside the

1 University of Warsaw. Instituto de Estudios Ibéricos e Iberoamericanos.

Correo-e: m.boguszewicz@uw.edu.pl; https://orcid.org/0000-0002-4042-2844.

2 University of Warsaw. Instituto de Estudios Ibéricos e Iberoamericanos.

Correo-e: m.a.gajewska@uw.edu.pl; https://orcid.org/0000-0001-7126-9179. 
screen, reflects the sociocultural context in which the film arises. In the conclusions we refer to the ambiguity of the interpretations of the feminine condition represented in the analyzed films. In spite of different attitudes of their authors towards the concept of matriarchy and in spite of using totally different languages, in the case of both films emerges their potential to deconstruct the myth of Galician and Basque matriarchy and to formulate a critical commentary about reality.

Keywords: Galicia; Basque Country; Documentary; Woman.

Sumario. 1. Introducción. 2. Matria de Álvaro Gago. 3. Amama de Asier Altuna. 4. Conclusiones. 5. Referencias bibliográficas.

Como citar: Boguszewicz, M.; Gajewska, M. A. (2020): "El matriarcado gallego, el matriarcado vasco: revisión del mito en Matria de Álvaro Gago y Amama de Asier Altuna”, en Madrygal. Revista de Estudios Gallegos 23 Núm. Especial, pp. 35-50.

\section{Introducción}

El objetivo de este artículo es el análisis de la representación de la mujer en dos producciones fílmicas: el cortometraje Matria de Álvaro Gago (2017) y el largometraje Amama de Asier Altuna (2015). Aunque ciertamente son materiales cinematográficos de un carácter claramente diferente (la duración, el género, el presupuesto, etc.), comparten el interés por la condición de la mujer en la sociedad en el contexto de las relaciones de poder. También es cierto que el estatus de la mujer y su poder social es, en gran medida, común para todo el Estado español. No obstante, se observa semejanza entre ciertos rasgos de las culturas gallega y vasca que son efecto de su situación legal. Ambas regiones, debido a las circunstancias históricas, tienen que negociar su identidad cultural y nacional con el centro político del país. Como resultado, a lo largo del proceso de la articulación ideológica y política del regionalismo y del nacionalismo iniciada básicamente en el siglo XIX, se iba creando el modelo de lo femenino profundamente marcado por la función procreativa de la mujer (Sabadell Nieto 2011: 44-45). La visión de la mujer como la madre de la nación, la que le asegura la supervivencia y la que la educa en el amor a la patria, fue especialmente intensa en las naciones sin estado (González Fernández 2009: 65) y se arraigó profundamente en su conciencia social. La fuerte presencia de la mujer en el imaginario nacional tuvo como consecuencia la falsa valoración de su poder social llevando incluso en el caso de Galicia y el País Vasco a la creación del mito del matriarcado.
La visión exagerada del peso social de la mujer en los territorios estudiados se vio reforzada por los factores de signo económico y religioso. Por un lado, tanto la costa gallega como la vasca implican la importancia de la cultura marina marcada por largas ausencias de los hombres en los hogares. Por otro, el interior queda afectado por la emigración transatlántica, cuyo auge coincide con la formulación de las tesis nacionalistas. Al factor migratorio y las ausencias alargadas del hombre se añade el peso de la Iglesia católica que mantiene a la mujer en su rol tradicional. Esta situación provoca el exceso de responsabilidades que se atribuye a la mujer sin respaldarlo con el aumento de los derechos correspondientes a estas obligaciones. En efecto, la mujer se encarga de las tareas tradicionalmente masculinas pero sin compartir con el hombre el poder. Aún así, en ambas regiones esta situación derivó en lo que se ha bautizado como el 'mito del matriarcado'.

Aunque en general la emigración contribuyó a la creación del mito, hay que señalar que en el caso de Galicia, la emigración tuvo también unos efectos positivos. En cuanto a los beneficios del éxodo masculino para la mujer, Castro y Reimóndez escriben:

Pero en todos os casos a emigración masculina supuxo tamén unha oportunidade para as mulleres e que ademais dos seus labores tradicionais como mariscadoras, redeiras ou peixeiras, víronse na obriga de substituír os homes á fronte do agro e máis da débil industria da época: as galegas foron a maioría nas fábricas de salgado, de conservas, de tabaco, de louza, de téxtil ou noutras industrias de fabricación de envases que, todas elas, reservaban aos homes os cadros de mando. (2013: 73)

De todas formas, así como adelanta la cita, a diferencia del País Vasco, cabe señalar la escasa industrialización de Galicia y, por lo tanto, la dificultad de la penetración del movimiento obrero y los postulados de la igualdad de sexo (Blanco García 1996: 61; Castro y Reimóndez 2013: 73). El peso de lo rural supuso además la supremacía de los valores tradicionales y las tendencias conservadoras así como el mísero nivel de la educación, especialmente entre la populación femenina (Blanco García 1996: 61). Varias estudiosas feministas insisten en el peso de la Iglesia católica en la situación de la mujer en Galicia a lo largo de la historia y el impacto negativo que esta tuvo en el desarrollo del feminismo y los derechos de la mujer (Blanco García 1996: 62; Agra apud Fente 2010: 374-376). 
Pese a las circunstancias adversas, el feminismo en Galicia gozó de una gran vitalidad siendo la patria de las famosas defensoras de los derechos de la mujer del siglo XIX como Rosalía de Castro, Emilia Pardo Bazán o Concepción Arenal. Ahora mismo, las gallegas gozan de los mismos derechos que otras ciudadanas españolas y destacan en ciertos campos de la acción feminista como el movimiento de base o el discurso teórico (Castro y Reimóndez 2013: 88-90). Igualmente, destaca la sensibilidad masculina sobre los problemas de la mujer como es el caso de la asociación Homes Galegos pola Igualdade. Esto no quiere decir, ni mucho menos, que se haya conseguido un equilibrio de poder entre los sexos. Como subraya María Xosé Agra: "Hai grandes declaracións, pero o día a día é moi molesto" (en Fente 2010: 376). La misma estudiosa hace una severa crítica del mito del matriarcado en Galicia:

Isto está desmentido. Non hai ninguén hoxe que poida soster que en Galicia houbo matriarcado. Iso formou parte da mitificación que se quixo facer da muller galega como muller forte, que aquí non necesitabamos o feminismo, porque as nosas mulleres traballaban. Iso ninguén con sentido común o defende hoxe. (...) O matriarcado utilizado como unha ideoloxía de encubrimento para facer ver que as mulleres teñen poder si é unha palabra pexorativa. Que hai un poder de mulleres, efectivamente, pero eu non lle chamaría matriarcado. As que manteñen a casa, coidan os fillos, traballan as terras, pero iso é a figura fundamental da nai, da transmisión de nais a fillas. Iso non é que eu entendo por matriarcado, iso ten máis que ver cos valores femininos que trasmiten as mulleres co sentido de tradición, da casa, valores que poden ser empregados para sometela pero que tamén poden ser valiosos en si mesmos. (apud Fente 2010: 385)

En suma, podemos constatar que no existe tal cosa como el matriarcado en Galicia y que el mito afectó de forma negativa a la situación real de las gallegas.
En el caso del País Vasco la convicción de la supremacía femenina dentro de la sociedad vasca tiene asimismo una base simbólica en la mitología local. A lo largo de años este convencimiento ha encontrado una gran inspiración en la reflexión etnográfica, antropológica, sociolingüística o histórica. La más relevante es la hipótesis del matriarcalismo vasco acuñada por Andrés Ortiz-Osés (1981)³. Según su interpretación en la tradición vasca la mujer gozaba de un importante rol simbólico de "carácter religioso-cultural y psico-social" que se debe a la relación de la madre-mujer con la madre Tierra personificada en Mari (2007: 55), un numen central en la mitología vasca (Barandiarán 2014: 86). Este concepto iba reproduciéndose en los escritos de otros estudiosos y llegó a popularizarse en la conciencia cotidiana. Sin embargo, como constata Teresa del Valle Murga, aunque la importancia de Mari dentro de la mitología vasca ha sido frecuentemente utilizada para subrayar el poder de la mujer en la sociedad y cultura vasca, se trata más bien de "una idealización del poder de la mujer, pero no un indicador del poder real" (1983: 435).

Otro estudio que tuvo bastante repercusión y supuestamente podía penetrar asimismo la conciencia popular, fue la teoría de la matrilinealidad de la cultura tradicional vasca, basada en un análisis lingüístico de términos de parentesco en euskera (Caro Baroja 1998: 159-160 $)^{4}$. A ello se suma una interpretación de las normas tradicionales que regulaban la herencia en el campo vasco. Las normas tendían al traspaso del patrimonio solamente a uno de los hijos, al que según la costumbre (posteriormente sancionada legalmente por el Fuero) designaban los padres en virtud de sus capacidades para encabezar el caserío. En el proceso de elección del heredero no se excluía a las mujeres (Aranzadi 2001: 899), lo que para los defensores de la tesis sobre el matriarcado vasco se convirtió en uno de los argumentos sobre la supuesta posición privilegiada de la

3 En sus trabajos posteriores se distanció de esta hipótesis, suavizando el tono de su argumentación y reconociendo como más oportuno el término "matrialismo" o "trasfondo matrial vasco" (Ortiz-Osés 2007: 55).

4 Julio Caro Baroja argumentaba que en la etiología del euskera podemos encontrar el reflejo del (supuesto) modelo matrilineal: "La palabra que sirve para designar la hija es alaba, mientras que para decir hijo se emplea la voz seme. Para designar a la hermana del hombre úsase la de arreba y para el hermano de la mujer la de neba: por último, la hermana de la mujer es aizpa mientras que los hermanos entre sí son anaiak. Es decir, que cuando se trata de fijar el parentesco entre hermanos y hermanas aparece el sufijo $b a$, pero no al designar a los hermanos cuando no se habla de ellos sin referencias a las hermanas, no en el nombre de los hijos varones y sí en el de las hijas. Estos es notable $\mathrm{y}$, en consecuencia, cabría pensar que nombres como el de osaba, oseba, osoba = tío; izaba, izeba = tía, y asaba = antepasado, se referían en un principio a la rama materna únicamente, que sería la más considerada y tenida en cuenta" (1998: 160). 
mujer. Sin embargo, basta con que se vea el estatus de la mujer en el contexto del que experimenta el hombre para constatar una obviedad: la falta de discriminación en la transmisión de herencia no significa ningún privilegio, sino más bien una tendencia igualitaria.

Aunque los investigadores usaron nociones como 'matriarcalismo' vasco - para referirse a la importancia mítico religiosa de la madre-mujer-o 'matrilinealidad' -para describir las antiguas relaciones de parentesco y sucesión- al habla y la conciencia cotidiana pasó solamente la noción 'matriarcado vasco', que supone un dominio económico-político de la mujer. Es más: a pesar de que desde los años 80 los investigadores están de acuerdo en que la interpretación popular del poder femenino en la sociedad vasca tiene poco que ver con la experiencia real de las mujeres en Euskal Herria, el 'matriarcado vasco' sigue siendo un referente simbólico de gran importancia (Aranzadi 2000, Bullen 2000, Mirgos 2010, Valle Murga 1985) que busca constantemente su reafirmación. En este sentido, la reflexión de los cineastas sobre el tema es especialmente importante teniendo en cuenta el impacto del cine en las sociedades actuales.

Por consiguiente, la elección del filme como el objeto del análisis se debe a la importancia de este medio de difusión artística y su carácter masivo y popular. Su capacidad de llegar al destinario es mayor en comparación con la expresión literaria y es reforzada por la inmediatez de la imagen. bell hooks ${ }^{5}$ subraya su poder desmesurado como la productora del saber (2003: 103). De acuerdo con esta lógica, la imagen no tanto reproduce lo visible sino que más bien hace visible ${ }^{6}$ la realidad que queda oculta tras los discursos dominantes y hegemónicos, incluidos los patriarcales. Esta característica de la producción fílmica, su poder de crear realidades paralelas y darles la legitimidad, es especialmente importante en el caso de las culturas que están alejadas de los centros de decisión política. Stuart Hall, sin ser el teórico del cine pero interesándose por su impacto social, invita a ver las películas "not as a second-order mirror held up to reflect what already exists, but as that form of representation which is able to constitute us as new kinds of subjects, and thereby enable us to discover who we are" (apud hooks 2003: 104). Resumiendo, el análisis de ambas producciones nos deja ver cómo se crean las identidades femeninas en la cultura gallega y vasca y cuál puede ser su lectura crítica.

La base del análisis es "el método antropológico-morfológico de obra fílmica" de Seweryn Kuśmierczyk (2014, 2015). La idea fundamental de este método es apoyar las interpretaciones tanto en el contenido como en los recursos estéticos empleados en las películas. Una interpretación derivada del argumento del filme pero separada de la reflexión sobre su forma carece de justificación y resulta insostenible, tal como se considera inaceptable una interpretación que se refiera tan solo a los aspectos formales. Las películas son realidades complejas, a veces polifónicas, pero dotadas de una coherencia interna. Para abarcar la película en su totalidad y complejidad Kuśmierczyk recomienda considerar durante el análisis cuatro pares de aspectos básicos: el contenido y la forma de la película, el tiempo y el espacio, lo visual y lo sonoro, $y$, por último, el protagonista y las referencias a la realidad sociocultural fuera del mundo representado (2015: 17). Entre los componentes de los pares hay una estricta relación y por consiguiente normalmente en la presentación de resultados todos los elementos se entrecruzan. El análisis simultáneo de varios aspectos de la obra fílmica permite descubrir cómo se configuran las 'redes de significado' dentro de la película y cómo se refieren a los planos temáticos que nos gustaría investigar. Al mismo tiempo se convierte en un 'laboratorio' para observar los significados culturales fuera del mundo de la ficción, o sea, los provenientes del mundo 'real', que se incorporan al filme de forma implícita.

La realidad fílmica, como una imagen sublimada e intensificada de la condición del ser humano y sus circunstancias (Dragovič 2012: 41) -de forma intencionada o no-alude al mundo fuera de la ficción. En este sentido

5 Seudónimo de Gloria Jean Watkins inspirado en el nombre de su bisabuela y, por decisión de la investigadora, escrito con minúsculas para atraer más atención a su mensaje que a ella misma (Encyclopaedia Britannica: https:// www.britannica.com/biography/bell-hooks).

6 Evidentemente, no podemos no referirnos aquí a la famosa constatación de Paul Klee de que al arte no reproduce lo visible sino que lo hace visible (por ejemplo en Gubern 2004: 21). 
podemos tratarla no solamente como un producto de poderes creativos de sus autores sino que también como una fuente de información sobre ellos mismos y el contexto sociocultural que los condiciona. En otras palabras, mensajes implícitos transmitidos por películas pueden carecer de coherencia con las intenciones del director.

\section{Matria de Álvaro Gago}

Matria dura 21 minutos y está rodada íntegramente en gallego. La trama se cierra en un día de vida de Ramona, mujer en sus cincuenta que vive en un pueblo costero y trabaja en una fábrica conservera. Su relación con el marido es distante y parece que lo único que la motiva es la relación con su hija y con su nieta. $\mathrm{Su}$ ritmo de vida es frenético por las exigencias que le impone su entorno: el marido, los superiores y la hija. Está llevada al borde de sus capacidades físicas y mentales: toma pastillas para mantenerse en pie pese a la debilidad de su cuerpo enfermo, se echa toneladas de desodorante para enmascarar el olor a sudor que produce su cuerpo en un correr continuo, se mosquea con la única persona que está realmente preocupada por ella, etc. Sin embargo, lo que parece ser un escenario dantesco, es, según el director del corto, la realidad cotidiana de miles de mujeres:

As narrativas mais atraíntes veñen dadas polo interés que suscitan as persoaxes. É imposible contar unha boa historia sen persoaxes e situacións críbeis e suxestivas. Aquí, o material cru existía e non estaba moi explorado. Sentía que facer este filme era a miña responsabilidade. Sentía que era o meu deber darlle voz a estas mulleres silenciadas que soportan, calan e tiran para diante, pero que tamén necesitan sentirse coidadas e queridas. O local é o que nos nutre. E do local ao universal, sen deixar indiferente: das alegrías e penas de Ramona ás alegrías e penas de todas as mulleres. Un traballo sobre un material existente para unha mirada honesta dun cine comprometido socialmente. (Gago, en línea $\left.{ }^{7}\right)$

El corto fue premiado en varias ocasiones pero el galardón que más atención atrajo fue el del
Sundance Festival. Con ese motivo, aparecieron varias noticias sobre el filme en los medios de comunicación locales y estatales. Las reseñas coincidían en valorar la producción como un aporte al cuestionamiento del mito del matriarcado en Galicia: "Matria trata de visualizar o 'falso mito' do matriarcado en Galicia" $\left(\mathrm{CRTVG}^{8}\right)$; "Matria (...) tumba el mito del matriarcado gallego" (El País ${ }^{9}$ ). Sin embargo, aunque en la mayoría de los artículos dedicados a Matria el director parece corroborar esta visión, en la entrevista de Bea Martínez (Beamos Producción) el mismo matiza:

[Matria] Surge de la necesidad personal de acercarme a Francisca [actriz principal], como persona, conocerla mejor, su contexto, su tierra, que es también la tierra de mi abuelo y de mi padre. Si bien no nos unen lazos familiares, la relación es muy próxima, pues trabajó cuidando de mi abuelo hasta que falleció. De esta relación surge la necesidad de trasladar a la pantalla su historia, y así poco a poco articular el discurso de su vida. Es a posteriori cuando se incluye la denuncia de las condiciones laborales en el trabajo de la conservera (no es algo exclusivo de las conserveras) y del mito del matriarcado gallego. (apud Martínez 2018, en línea ${ }^{10}$ )

Aún antes del estreno (mayo 2017), Gago publicó en YouTube un clip titulado "MATRIA Tra-la camara con 'Matriarcas' de GuadiGalego" con la dedicatoria a "todas as MATRIARCAS da terra dun tal Breogán"11. Así y todo, un corto que empezó como una historia personal, se convirtió en un mensaje sobre un problema mucho más universal. Contando sus experiencias de Sundance, Gago habló de la reacción del público de los Navajo, una tribu considerada matriarcal, que se había reconocido en la película y se había identificado con la protagonista (apud Martínez 2018, en línea ${ }^{12}$ ). No obstante, es importante tener en cuenta la intención inicial del cineasta ya que esta determinó el modo de ejecución de la producción.

Matria es difícil de clasificar genéricamente aunque es evidente que bebe de la tradición del documental. Richard Barsam and Dave Monaham definen el documental por el criterio

\footnotetext{
https://www.alvarogago.com/matria.

http://www.crtvg.es/informativos/matria-de-lvaro-gago-gran-premio-do-xurado-en-sundance-3620299.

Huete 2018: https://elpais.com/cultura/2018/01/31/actualidad/1517408272 817446.html.

http://beamos.es/entrevista-al-cineasta-gallego-alvaro-gago-creador-de-matria-parte-i/.

https://www.youtube.com/watch?v=dR6Yvr7HHok.

http://beamos.es/entrevista-al-cineasta-gallego-alvaro-gago-creador-de-matria-parte-i/.
} 
de la 'lealtad' y en contraposición al cine narrativo: "We might say that narrative film and documentary film differ primarily in terms of allegiance. (...) In other words, if we think of a narrative movie as fiction, than the best way to understand documentary film is as nonfiction" (2019: 69). No obstante, la película de Gago no cabe en esta definición. La historia contada en el corto es inventada y el personaje de Ramona es ficticio. Por lo tanto, parece más acertado recurrir a la matización que hace sobre el documental Bill Nichols (2010: 99):

This is a matter of emphasis rather than either/ or alternatives, and many documentaries make frequent use of poetic and narrative storytelling techniques as well as rethorical ones. (...) Even when a documentary is distinctly poetic in form, a rhetorical emphasis turns attention toward the viewer and her view of the world. The form of the work draws less attention than its perspective on the world.

Esa ambición de documentar y poner al debate un problema social es lo que hace de Matria una película más próxima genéricamente al documental. Sin embargo, el corto de Gago comparte también una serie de características con otros géneros. Además del cine de ficción, también el experimental. Según Barsam y Monaham (2019: 75), el cine experimental tiene el carácter personal y no es comercial. Sobre lo primero ya hemos escrito más arriba. En cuanto a lo segundo, el corto de Gago no dispuso de una gran industria cinematográfica y se promocionó en gran medida gracias a unos canales de difusión alternativos, como Vimeo. Todos estos rasgos mencionados arriba (premios en los festivales, hibridación entre la ficción y el documental, producción al margen de la industria) definen a la corriente del cine de vanguardia en Galicia denominado el Novo Cinema Galego que se convirtió en un referente internacional. Buscando un denominador común para el conjunto de directores muy diversos, Pablo Suárez (2014: 124) resume: "O 'Novo Cinema Galego' é un movemento recente que agrupa unha serie de creadores galegos de vanguarda con recoñecido prestixio internacional e que traballan á marxe da industria”. Romero Suárez, además, puntualiza que en el caso del Novo Cinema Galego: "Podemos hablar con seguridad de una clara predilección por el trabajo con la realidad a través de los diferentes géneros que ofrece el cine documental así como una tendencia hacia la ficcionalización de la realidad" (2015: 16). Podríamos entonces concluir que Matria es una producción situada en un espacio fronterizo tanto en lo referente al sistema de producción y distribución así como el del género. Esta actitud es una práctica hoy en día ampliamente difundida en el mundo cinematográfico universal, especialmente entre las generaciones nuevas de los directores (Barsam y Monahan 2019: 81).

Aunque Matria es de autoría masculina en lo que se refiere a la dirección, también comparte ciertos rasgos con el 'cine de mujeres'. Como afirma Alison Butler: "Women's cinema is a notoriously difficult concept to define. It suggest, without clarity, films that might be made by, adressed to or concerned with women, or all three" (2002: 1). Katarzyna Paszkiewicz precisa que "el cine de mujeres no es un simple corpus definido por el género de sus autoras (o espectadoras), sino más bien un espacio discursivo complejo, donde confluyen diversos procesos históricos y culturales que han excluido o marginado a las mujeres de la producción cultural" (2017: 11). Para resolver el problema de la terminología, Barbara Zecchi propone la noción del 'gynocine' que incluye todas las personas implicadas en la producción fílmica, no sólo directores (2014: 8) ${ }^{12}$. De acuerdo con esta propuesta, Matria cumple los requisitos para hablar de un 'cine de mujeres'. Entre el equipo no faltan los nombres femeninos: María José Domínguez y Mireia Graell Vivancos (productoras ejecutivas), Lucía C. Pan (fotografía), Alba Aguiar (directora artística) y muchas más. En definitiva, sin hablar del 'cine feminista', podemos tratar Matria como una mirada atenta a las cuestiones feministas y con una voz importante de las mujeres.

La historia presentada en el filme se inspira en un personaje real, el de Francisca Iglesias Bouzón, que es a la vez la actriz que interpreta el papel de la protagonista. Como Iglesias Bouzón es una persona próxima al director, la producción empieza con una intención de contar una historia personal pero termina adquiriendo un significado de mayor alcance social. Todas estas circunstancias determinan la forma de contar la historia. La distancia entre la protagonista y la cámara es por lo general estable

12 La misma información es accesible también en la página web del proyecto Gynocine: https://www.gynocine.com. 
respetando el espacio íntimo de Ramona pero sin alejarse de ella. De modo que el espectador se convierte en un observador silencioso de un día de trabajo de Ramona que se organiza entre la casa, la fábrica y la escuela de su nieta. Estos tres espacios constituyen tres ejes narrativos de la historia y cada uno de ellos está diferenciado visualmente y sonoramente. Asimismo, cada uno de ellos está condicionado por una figura masculina explícitamente o implícitamente presente en la trama: el marido, el jefe y el yerno. De esta forma, la identidad de Ramona como esposa, madre y trabajadora se está construyendo sobre el poder fáctico de los tres hombres.

La historia se inicia en la madrugada cuando Ramona se levanta para ir al trabajo. En estas escenas dominan los tonos oscuros y el silencio. Aún es de noche, su marido está durmiendo en la cama matrimonial. Se oye sólo el freír apresurado de la comida y el susurro silencioso de la ropa que Ramona se pone en el dormitorio. La cámara está atenta a cada movimiento del personaje que está en el centro del plano menos en un momento en el cual le da el protagonismo al marido: cuando Ramona se prepara para salir, el marido se mueve molesto entre las sábanas. Otro momento de ruptura con el carácter general de las tomas es aquel en el que Ramona se mira en el espejo. En esta escena, el espectador contempla a 'dos Ramonas': una de espaldas y la otra de frente con una cara de reflexión. Este momento es especialmente importante y como tal fue el más expuesto en la campaña de promoción del corto. En el correr diario de Ramona no hay lugar para las reflexiones. Las reflexiones, además, son peligrosas por lo subversivo que pueden conllevar. Ese momento de la reflexión es el germen de su revolución interior. Es el día de poner en cuestión la dinámica cotidiana, es decir, no sólo resistir, como lo hace normalmente, sino precisamente romper con las reglas. La sensación de injusticia genera en la protagonista una serie de emociones que constituirán la fuerza subversiva de la historia. Por consiguiente, la escena del espejo es el momento clave de la trama y se traduce en el suspense. En el espectador se genera la duda de si el personaje saldrá o no de su rutina diaria $\mathrm{y}$, a consecuencia, cambiará su vida. La trama del corto no da una respuesta clara a esta pregunta y mucho menos crea un desenlace feliz.

Entre el espacio de la casa y el del trabajo, se extiende un territorio intermedio que Ramona recorre en su bicicleta. Cuando sale de casa con el canto de gallo, la calle del pueblo se está llenando de otras mujeres, andando con las bolsas de plástico en la mano o montando en las bicicletas. Todo está dominado por la luz grisácea del día que está empezando. Ese gris será la tonalidad dominante en todas las escenas exteriores. Incluso cuando a mediodía sale el sol, la protagonista y su alrededor permanecen oscuros. Los pasajes en la bicicleta constituyen unas escenas largas, reflexivas, en las cuales unas veces el espectador puede contemplar las emociones en la cara de Ramona y otras sólo ve a la protagonista desde lejos. Con el transcurso del día, el pedaleo acelera y aumenta la sensación de la creciente tensión: Ramona tira la bici al suelo o está llorando mientras pedalea ferozmente.

La escenografía de la fábrica tiene el carácter estéril y deshumanizado propio de los espacios industriales. Así como en la casa y en la calle, domina la sombra y los tonos grises con una sóla excepción: el despacho del jefe. La cámara lo deja ver sólo un corto momento cuando está contemplando atentamente la sala desde lo alto de su ventana. El contraste entre el espacio 'femenino' y 'subordinado' es colosal. La figura del jefe está situada en un entorno luminoso y de colores intensos lo que provoca la sensación del bienestar del personaje e impone el poder sobre el otro espacio. En cuanto a este último, los efectos sonoros aumentan la impresión lúgubre que provoca el ambiente del interior de la fábrica. El sonido de las máquinas es molesto, cansado y monótono. A eso se suma el griteo constante de la encargada que con su voz fuerte no deja de presionar a las trabajadoras y animarlas al esfuerzo con un discurso machista repleto de palabras y expresiones sexistas: "Hoxe rascas a cona todo o día", "a madre que vos pariu", "á puta calle", "vindes pola mañá coa coña forjada" etc. El interior está poblado únicamente por las mujeres y el mensaje es claramente humillante para sus destinatarias: "non merecedes este traballo", "pareces unha inútil", etc. La encargada se dirige a las empleadas por los números en vez de los nombres lo que aumenta la sensación de un sistema deshumanizado y explotador. De forma que las escenas en la fábrica señalan también la situación precaria de las obreras. Las mujeres gallegas fueron desde el principio de la industrialización de Galicia uno de sus pilares. Especialmente en el caso de la conservera, el papel de la mujer es innegable:

En Galicia la fuerza laboral femenina en la pesca existe hoy en día con carta de naturaleza 
propia, con arraigo histórico y con un papel socioeconómico determinante para la elaboración del producto pescado. El papel de las mujeres en la pesca gallega es fundamental para el desarrollo de muchas de las actividades del sector, desde la extracción del recurso, pasando por la transformación, comercialización y servicios relacionados. Algunos de estos pasos en la cadena productiva de la creación del producto pescado tienen un carácter eminentemente femenino, como son el marisqueo y la fabricación de conservas y otros transformados de la pesca. (García Negro y Zotes Tarrío 2006: 23)

Esta situación excepcional de Galicia en relación con el resto del estado se debe a las circunstancias históricas determinadas, sobre todo la emigración masculina intensa del siglo $\mathrm{XX}$. En consecuencia, el mercado de trabajo en esta región fue más accesible para la mujer pero al mismo tiempo más desequilibrado y menos regularizado. Así y todo, Galicia presenta hoy en día unos datos preocupantes en cuanto a la diferencia salarial por razón de sexo (Pena Boquete 2009: 3). Por lo tanto, el filme de Gago pone en cuestión también el mito de la posición privilegiada de la mujer en el mercado laboral gallego desvelando las prácticas opresivas y discriminatorias de su trabajo en la paradigmática industria conservera (y por extensión la industria en general).

El tercer espacio clave que aparece en el filme es la escuela de la nieta de Ramona. En este caso el contraste con las otras escenas es muy marcado así como sucede en la toma del despacho del jefe descrita arriba. Al entrar por la puerta de la escuela, la protagonista pasa a otro mundo: lleno de luz, colores intensos, las voces animadas de las niñas. La misma protagonista experimenta esta transformación: se calma, su cuerpo se relaja, la cara emana alegría por ver a la hija y a la nieta. No obstante, la escena final pone en duda el desenlace feliz: así como en la escena inicial delante del espejo, la cámara se acerca a la cara de Ramona que se vuelve reflexiva, ausente y agobiada. De esta manera, Ramona se convierte en lo que Sara Ahmed denomina 'paria afectiva': "casarse, tener hijos, no se convierten solo en cosas que ha hecho, cosas que ha logrado en su vida, sino también en cómo se pierde a sí misma por el camino" (2018: 87). Sin embargo, ese deber de felicidad normalizada se impone no sólo en los espacios privados sino también en los públicos. Por lo tanto, Ramona está "alienada de sus brazos, cuando estos brazos se ponen al servicio de la maquinaria industrial" (Ibid.: 88). De forma que, aunque la protagonista encaja en la imagen de la madre y esposa tradicional, no puede sentirse feliz pese a disfrutar de la relación que le une a su hija. Asimismo, la condición de ser una empleada asalariada no le aporta la independencia que se supone que genera un ingreso propio. Todos estos 'requisitos' de felicidad son impuestos socialmente en una situación en la cual el sistema en sí impide a las mujeres sentirse las dueñas de su existencia.

Los espacios se relacionan con las personas con las cuales Ramona suele interactuar, de forma directa o indirecta, en su vida cotidiana. Por lo tanto, la relación que establece con cada una de ellas es a la vez la relación con el espacio determinado. La dimensión física del entorno condiciona las relaciones humanas y las hace vulnerables. Judith Butler plantea el problema de vulnerabilidad del ser humano en el contexto amplio de la interdependencia entre varios factores de carácter material e inmaterial:

En realidad, la vulnerabilidad no puede ser concebida de manera limitada, como un efecto restringido a una situación contingente o como una mera disposición subjetiva. Al ser una condición que coexiste con la vida humana -concebida como vida social y ligada al problema de la precariedad-, la vulnerabilidad es el nombre atribuido a una cierta manera de apertura al mundo. En este sentido, la palabra no solo designa una relación con dicho mundo, sino que afirma el carácter relacional de nuestra existencia. Decir que cualquiera de nosotros es un ser vulnerable es, por tanto, establecer nuestra dependencia radical no solamente respecto a los otros, sino respecto a un mundo continuo. Y esta cuestión tiene implicaciones en el momento de comprender quiénes somos, como seres apasionados, sexuales y ligados a los otros por necesidad, pero también como seres que intentamos persistir, entendiendo que esa persistencia puede y está en peligro cuando las estructuras sociales, económicas y políticas nos explotan o nos malogran. (2014: 48)

Las relaciones afectivas de Ramona se sitúan entonces en los tres espacios analizados: la casa, la fábrica y la escuela. Las escenas exteriores en la bicicleta son en este sentido 'la tierra de nadie' en la cuál Ramona se encuentra consigo misma y constituyen territorios liminales, fronterizos, con todo el potencial subversivo que esta condición supone. El primer escenario que se contempla en el corto es la casa que Ramona comparte con su marido. Entre los esposos domina la frialdad y distancia. La comunicación entre ellos es casi nula y las pocas palabras que se dirigen son pronunciadas con 
una tensión visible y una hostilidad encubierta. A las preguntas del marido sobre el cumpleaños de la nieta, Ramona responde: "A ti, que carallo che importa?". Ramona continuamente recibe sus llamadas en el trabajo pese a que no es permitido hablar por teléfono en las horas laborales. Intenta oponerse a la presión que le ejerce su marido que quiere que su esposa vuelva a casa en la pausa de comida. Ramona se niega, pero sus respuestas desvelan la dependencia sicológica. Por mucho que diga que no, al final va a la casa para atenderle. A esto se suma la supuesta infidelidad de su esposo. No sabemos si los rumores son ciertos o no, pero, cuando la protagonista se desmaya y su amiga le pregunta que le pasa, las otras obreras están bromeando: "O seu home fode con todas menos con ela". En algún momento, la amiga llega a decirle a Ramona: "Mándao a rascar o carallo" a lo que esta replica: "Ti métete no teu".

Es precisamente la mencionada amiga el personaje que se relaciona con el espacio laboral aunque a este espacio pertenece también la interactuación con la encargada, las otras empleadas y, de forma indirecta, el jefe. Sin embargo, es la amiga la cual establece el vínculo afectivo más potente en ese entorno. Ese vínculo se manifiesta en varios momentos de crisis que la protagonista está enfrentando ese día. Tanto el tono de la voz, como la forma y el mensaje transmiten preocupación y cariño: "Estás ben? Tes mala cara. Non durmistes ben?". Sin embargo, el tono de la respuesta desvela la irritación e impaciencia de la protagonista: "Máis ou menos". En otras ocasiones, pasa lo mismo. Cuando se desmaya, la amiga la sostiene preguntando si está bien pero Ramona sólo le contesta secamente: "sí". Como el espectador es consciente de que esa actitud de la protagonista es el resultado de la reflexión matinal, sus reacciones a las preguntas de la amiga aumentan la impresión de desesperación y determinación.

En cambio, la relación con la hija es claramente llena de cariño y paciencia. Ramona coje todas sus llamadas, incluso en la fábrica, y contesta con preocupación y una disposición absoluta a acudir a su ayuda cuando haga falta. Cuando la hija la llama por la mañana, camino al trabajo, Ramona pregunta de inmediato: "Que pasa? Estás ben? Queres que vaia alí?" Y añade: "Non te olvides de tomar as pastillas". Así como su hija se lo ha pedido, en la pausa de comer recoge de la tienda el regalo para su nieta lo que supone un esfuerzo adicional. Paga por el regalo 20 euros, que le parecen muchos, pero no quiere que la hija se los devuelva: "Non lle compramos nunca nada á nena". Mientras tanto, Ramona no puede llamar de su móvil para preguntar por otro empleo porque se le ha acabado el crédito, lo hace desde el teléfono del bar. Una de las pocas escenas en las cuales la cámara deja de seguir a la protagonista es cuando Ramona habla con su hija por teléfono en el baño en la fábrica. La imagen se estabiliza enfocada en el centro del baño por el cual una y otra vez pasa la protagonista en un frenético ir y volver. Así como en la escena con el marido en la madrugada, el protagonismo se le pasa por un intre a un personaje que no está o no se ve con claridad, pero que es crucial para el desenlace de la trama.

Las figuras masculinas o no aparecen o aparecen poco. Sin embargo, son figuras claves en el mundo de Ramona. Pese a la distancia y hostilidad en las relaciones con su marido, la mujer no cuestiona su poder. Lo provoca con sus réplicas pero se somete a la lógica patriarcal: se levanta temprano para prepararle la comida, vuelve apresuradamente del trabajo para calentársela y dar de comer a las gallinas aunque él está en casa.

Lo mismo pasa en las relaciones laborales. Ramona desafía el poder de la encargada, dentro de ciertos límites. Se dirige a ella con su nombre, Logia, le pregunta si puede salir antes, si puede ir al baño en las horas del trabajo $\mathrm{y}$, sobre todo, en un momento de tensión entre la encargada y una obrera nueva, se atreve a contradecirle. No obstante, el poder de Logia es restringido por su superior que la está observando atentamente desde lo alto. Así como ya queda dicho arriba, la figura del jefe se manifiesta sólo un rato pero la escena es muy sugestiva. El hombre adopta una actitud de poder: está de pie, firme, con los brazos cruzados, en una posición de poder. Con una sola mirada le señala a la encargada su negligencia en no disciplinar a una de las trabajadoras. La encargada le devuelve una mirada de plena subordinación. Ella es sólo un eslabón en la máquina patriarcal. En cuanto a la escuela, la figura del hombre es representada sólo en un nombre mencionado en un corto intercambio de palabras entre la madre y la hija. Ramona pregunta: "Que tal Lois?". A lo cual la hija contesta que ha tenido la entrevista lo que sugiere que no tiene trabajo. Tampoco está en el partido de su hija y su ausencia resuena aunque las dos mujeres no parecen darse cuenta de eso.

Además de estos tres personajes masculinos, hay un momento más en el cual aparecen los hombres. El bar donde entran por la mañana 
Ramona y su amiga para pedir bocadillos, está lleno de hombres tomando cervezas, riéndose y echando piropos vulgares y sexistas.

Por lo tanto, los roles femeninos y masculinos en el filme no se presentan de acuerdo con las normas sociales tradicionales: el hombre trabaja y la mujer cuida de la casa y de la familia. En Matria, los hombres ni trabajan ni se encargan del cuidado de la casa ni de los deberes familiares. En cambio, las mujeres, además de sus responsabilidades tradicionales, cargan con el peso adicional de mantener a la casa y ayudar a la familia económicamente. El hecho de convertirse en las proveedoras de los hogares en términos capitalistas, no les sitúa en una posición privilegiada. Todo lo contrario, los hombres conservan su poder mientras las mujeres, enredadas en las obligaciones que no son capaces de cumplir y luchando desesperadamente por mantenerse en la superficie, pierden todo el potencial subversivo que su condición de asalariadas les pueda aportar. En este sentido, se nota la referencia a la tradición feminista gallega propia, causada por las ya mencionadas circunstancias históricas que generaron la emigración masiva transatlántica. Ramona y otras mujeres en una situación parecida, serían entonces la versión moderna de las "viudas de vivos" de Rosalía de Castro. Sin embargo, el grito de "Yo también navegar" de Xohana Torres que expresaba la oportunidad de adoptar una actitud activa, en el caso de 'las Ramonas' parece utópico. Por mucho que la protagonista intente rebelarse, el sistema no se lo permitirá. En la escena final, la hija se inclina para oler a su madre y pone una cara de burla. Ramona reacciona con una risa casi histérica que pronto se apaga. La mirada seria de Ramona transmite la sensación de impotencia y rendimiento ante una fuerza mayor.

\section{Amama de Asier Altuna}

La película vasca Amama dispone de un lenguaje totalmente distinto. El argumento está envuelto en varias referencias tanto a la cultura tradicional vasca como al arte y la literatura contemporánea, conservando al mismo tiempo plena coherencia entre sus elementos. Entre ellas podemos encontrar por ejemplo el bosque de Oma ${ }^{13}$ cuyo concepto, creativamente modificado, tiene su reflejo en la realidad interna del filme o el poema "Maite zaitut, ez" de Kirmen Uribe (2003) que inspiró el núcleo de la trama.

En cuanto al mundo de la ficción propiamente dicho, la película absorbe varios elementos de la cultura tradicional vasca, pero sobre todo se nutre del motivo de la diosa Mari. Es la deidad máxima dentro de la mitología vasca: un ser de carácter telúrico y solar, que representa tanto las fuerzas de la naturaleza, como los valores culturales. Puede adoptar forma de un fenómeno atmosférico o natural, un animal o una mujer hermosa y sabia autoridad. Por eso se suele entender como un numen que abarca todo, una gran síntesis de la realidad física, sociocultural y espiritual (Barandiarán 2014: 22, 47-48, 86-103; Ortiz Osés 2007: 31-35). La película recurre a esta naturaleza múltiple a través de recursos estéticos y narrativos.

Amama, rodada enteramente en euskera, a través de contar la historia de una familia que vive en un caserío, representa un enfrentamiento entre los valores tradicionales y la modernidad. Mientras que los padres, ya entrados en años, siguen antiguos modelos de comportamiento, sus hijos optan por otro modo de vida. Su hijo mayor decide emigrar al extranjero, otro, que vive con su familia en la ciudad, viene al caserío solo de vez en cuando, para ayudar en tareas agrícolas más duras. La única hija que tienen, la protagonista principal, es una artista que, a pesar de seguir habitando el caserío, es la que más experimenta este conflicto generacional. Es una familia cuyos miembros se respetan y quieren recíprocamente pero resultan incapaces de comunicarlo. $\mathrm{La}$ parte central de la trama se enfoca en la relación compleja entre la hija, Amaia, y su padre, fuertemente marcada por la imposibilidad de comunicación.

La familia tiene costumbre de plantar un árbol con cada nacimiento. Los árboles que corresponden a los personajes se pintan de un color asignado por amama, la abuela. Los colores que elige son metáforas de características y aptitudes de cada uno de los familiares. La película menciona tres árboles, que corresponden a Amaia y sus dos hermanos. Al hermano mayor, Gaizka, amama le asignó el color rojo, que, según nos cuenta la protagonista principal, simboliza "la fuerza, la sangre y la pasión"

13 El Bosque de Oma es una obra del pintor escultor Agustín Ibarrola realizada en Vizcaya que se forma de varias series de pinturas sobre troncos de árboles que representan figuras humanas, animales y figuras geométricas. 
y está reservado para el heredero del caserío. Al otro hermano, Xabi, le pintó al nacimiento el árbol de blanco, el color para "el vago, el flojo, el blando". Por último, a Amaia le pertenece el árbol pintado de negro, el color "del diablo y de las sombras" que ha de concordar con su condición de rebelde, contestona y "la mala" de la familia.

Como comenta Amaia, los colores condicionan la vida entera de los hermanos como si su destino "surgiera en el neolítico y hubiera llegado hasta hoy a través de la abuela como la única intermediaria". Por una parte, la vida de los personajes resulta determinada por condiciones fuera de su voluntad, por las cuales algunos de ellos pueden sentirse atrapados, otros presionados, dolidos o provocados a rebelarse, pero de las cuales, al fin y al cabo, no pueden huir ${ }^{14}$. Por otra parte, a través de este comentario se fundan los primeros vínculos entre amama y el tiempo mítico, que definen nuestra percepción de la protagonista desde una de las primeras escenas. Además, los colores rojo, blanco y negro coinciden con los tres colores más importantes que reaparecen en la mitología vasca. Más aún, se consideran colores vinculados a la diosa Mari que integra en sí "tanto el Negro de su caverna telúrica como el Rojo de su ascenso solar" y el color Blanco "como Alma Lunar del universo" (Otriz Osés 2007: 73). Los tres colores reflejan todas las dimensiones de este numen. Amama, asumiendo las responsabilidades rituales de la familia, en el acto de "pintar los destinos" de sus nietos se autoidentifica como la transmisora de su mensaje.

Con los tres colores concuerda la estructura del filme, partida en tres historias que se refieren a los tres hermanos. La parte más desarrollada se dedica a la protagonista principal. Sin duda alguna, cada una de las historias se relaciona con las restantes y nos aporta una perspectiva complementaria. Dentro del mundo de la ficción de Amama, se marca fuertemente la presencia de los hombres y las relaciones de poder y prestigio son dispersas. En cuanto al modelo de la feminidad, el largometraje vasco proporciona tres modelos, encarnados por tres personajes femeninos: Amaia, su madre y su abuela. A estas por su parte corresponden tres planos del mundo de la ficción: la realidad, en la que transcurren los hechos de la vida de la familia; el plano artístico, en el que se representan las obras de Amaia y, por último, el plano fantástico (o mitológico), que suministra un comentario a los hechos narrados. Cada uno de estos planos utiliza recursos visuales particulares: la realidad empírica de los protagonistas mantiene tonos neutros, la realidad mítico-fantástica se representa con los colores fríos y los vídeos de Amaia rodados con película de $8 \mathrm{~mm}$ de ancho ${ }^{15}$, representados con el efecto de imagen un poco borrosa, con varias manchas.

Con el plano "real" o "cotidiano" se puede relacionar la madre de Amaia. Como la señora de la casa se encarga de rituales relacionados con la muerte (es ella quien se ve obligada a cumplir con deber de encender cada noche una vela en honor de su padre fallecido), prepara la comida para toda la familia y se encarga de hacer conservas de los productos agrarios del baserri, o sea asume las responsabilidades que tradicionalmente se les atribuía a las mujeres (Homobono 1991, Valle Murga 1983). A ello se suman labores agrícolas que realiza bajo la instrucción de su marido ${ }^{16}$. Aunque la vida de los dos queda marcada por un trabajo físico muy duro, y aparentemente comparten los mismos valores, la posición de señora de la casa carece del prestigio del que goza su marido. Ni siquiera conocemos su nombre. Es callada

14 La impresión del destino como algo predeterminado aumenta el ramo estructural de la película: en el mismo principio, antecediendo los créditos iniciales, aparece una escena que descubre lo que pasa al final de la película. La escena de apertura en este caso marca el punto al que -independientemente de las acciones y las decisiones tomadas por los protagonistas- inevitablemente tiende el argumento.

15 Lo más probable es que el material fuera rodado como el resto del filme y el efecto se añadiera ya en postproducción. Sin embargo las "verdaderas" grabaciones realizadas durante el rodaje en el formato Súper-8 por Iraia Elías, Amaia, en el reparto se pudo ver antes del estreno de la película en una exposición que se había organizado en el marco de la promoción del filme.

16 En la cultura vasca tradicional existía una división muy clara entre labores femeninos y masculinos. Las tareas del campo y del establo eran las tareas del hombre, sin embargo la mujer también tomaba parte en ellas, pero siempre "bajo la dirección" del señor de la casa (Barandiarán 1974: 62; Homobono 1991: 104). De este modo la imagen de la madre de Amaia se asemeja a la visión de la mujer de los clásicos textos etnográficos sobre la estructura de la familia vasca. 
y sumisa. Como dice Amaia, la madre lleva toda la vida trabajando y obedeciéndole a su marido sin la menor queja. La única vez que se le opone es cuando quiere forzarlo a arreglar la relación con la hija. Pues, el valor más importante es para ella la integridad de la familia. Sin embargo, las medidas que toma para conseguirlo, es decir una silenciosa protesta unida con abstención de cualquier trabajo y un chantaje emocional, no funcionan. El que consigue animar al padre a cambiar de actitud es su hijo Xavi. A pesar de todo ello, la madre acepta su situación y considera el baserri su lugar en el mundo.

En cambio, la postura de Amaia frente a la vida, conforme a la simbólica del color que le asignaron, consiste en constante rebeldía. El negro que condiciona su destino predomina asimismo en su arte y la vestimenta que lleva. Es la única que se atreve oponer abiertamente a la voluntad de su padre y cuestionar su forma de vivir y entender la realidad. La protagonista es consciente de las diferencias fundamentales entre su padre y ella misma. Reconoce que viven "en otros mundos". El mundo de su padre cabe en los límites del caserío, el único lugar en el que se siente libre. La manera en la que Amaia lo describe implica cierto cariño que no se refleja en sus interacciones mutuas. El padre reprocha a sus hijos haber elegido otro camino que el de ser labradores y -aunque ya no le quedan tantas fuerzas que antes- planta tantas semillas como siempre porque, como afirma, "conservan la sabiduría de los antepasados" de la familia. Reproducción de los ciclos de cultivo significa el mantenimiento del contacto con esta esencia mítica que determina su identidad. El padre, como el cabeza de la familia, se siente personalmente responsable de preservar este contacto. Según Amaia, los modos de vida diferentes al de su progenitor por los que optaron sus hermanos y ella misma significan una ruptura del "vínculo con el neolítico".

Sin embargo, Amaia no pretende desvincularse de sus orígenes, ya que, es la tradición y el contexto local lo que acciona y condiciona su creatividad artística. Su relación con el baserri es tan fuerte que cuando se traslada a la ciudad después de una discusión con su padre, que en una furiosa pasión cortó el árbol de su hija, se siente incapaz de seguir preparando la exposición. Tampoco puede liberar sus emociones, ya que como a su padre, le faltan moldes de expresión abierta de lo que siente. El arte es su manera de comunicarse con el mundo y con ella misma, su manera de conocer lo que la rodea y de autodefinirse. Le permite traspasar los límites de lo lógico, lo empírico y conocer sus propias raíces.

Amaia trabaja sobre fotografía y cine experimental. En este sentido, empleando formas modernas, y al mismo tiempo enfocando su creación en ideas e imágenes propias para la tradición, une lo contemporáneo con lo antiguo. Vive un enfrentamiento entre los valores representados por el caserío y los representados por la ciudad, sintiendo por un lado, que el cambio que supone la muerte del caserío es inevitable y además, que ella misma ya no podría vivir como sus antecesores. Por otro lado, le da pena enterrar el antiguo mundo al que sigue estando vinculada. Su intención de captar el mundo que está a punto de desaparecer implica cierto distanciamiento y sugiere la misma postura que, en su tiempo, manifestaban los folcloristas al iniciar la recogida de costumbres, cuentos, creencias y otros elementos de las culturas tradicionales. La catalogación del patrimonio cultural (e incluso denominar algo un "patrimonio") es una señal de que el objeto de su interés se considera en peligro de extinción, pasa de ser algo "vivido" e integrado con la experiencia personal a ser algo "descriptible" y ajeno. En el caso de la visión que nos ofrece Amama cabe preguntar si realmente se trata de una definitiva elipse de lo esencial del mundo que representa o tan solo de una redefinición de la forma de su existencia.

El tema principal de las obras de Amaia es la naturaleza, mientras que el personaje que vuelve a aparecer constantemente es amama. Como afirma la protagonista "hace 80 abuelas vivíamos en el neolítico"17. El neolítico dentro del mundo representado es un principio del tiempo, un tiempo mítico. Las abuelas garantizan la unión mística con este principio, como una emanación de la "esencia" de la identidad. En varias fotos y grabaciones la abuela aparece junto con asociaciones vegetales: rodeada de frutos de cosecha, con mazorcas de maíz envueltas en su pelo que parecen formadas en una corona, o pisando descalza las yerbas.

17 La frase es una cita del ensayo Quousque Tandem de Jorge Oteiza, uno de los máximos representantes de la Escuela Vasca de Escultura. 
Parece estilizada de una deidad de cultivo y naturaleza y representar de esta manera la diosa Mari. En otras se representa inmóvil, con la mirada mayestática y el pelo suelto que se mueve con el viento o con la imagen multiplicada que alude a las mencionadas ochenta abuelas y el vínculo a lo más antiguo: los principios míticos. Su presencia en el arte de su nieta, como el símbolo de los lazos con los antepasados, descubre la relación compleja de la artista joven con sus raíces. Amaia rechazando los valores tradicionales representados por el padre (tales como su ethos del trabajo y la estructura social que encarna) que se pueden identificar como fundamentalmente patriarcales, queda impresionada por la espiritualidad y misticismo representados por amama.

Amama aparece asimismo en varias escenas fantásticas que suministran un comentario adicional al argumento, sugiriendo la interpretación de los hechos que se relatan. Por ejemplo en una de ellas vemos a Gaizka atado con una cuerda cuyo extremo está agarrando por "varias" amamas o más bien por su reproducción múltiple. Gaizka intenta liberarse estirando la cuerda hasta romperla. Una secuencia más tarde, ya en el plano real, vemos a Gaizka despidiéndose de la familia antes de irse del País Vasco. Gracias a la escena simbólica sabemos que si el personaje se va, es para siempre. Otra cuerda aparece en la escena en la que el cuerpo de amama después de su muerte aparece unido a través de una cuerda con una cueva, otro atributo de la diosa Mari (Barandiarán 2014: 86; Ortiz Osés 2007: 26).

Sin duda alguna, amama aparece también en la dimensión "real" de la trama. En la mayoría de las secuencias la vemos inmóvil, con el rostro majestuoso y una mirada ausente, fija en un punto. Por eso se parece más a una figura que una persona real. El efecto aumenta por el empleo de los acercamientos desde el plano medio hasta el detalle, enfocado en los ojos, acompañados por la música que a medida que el fotograma va limitándose a la cara, se hace cada vez más caótica. Sin embargo, lo que resulta más llamativo en la manera de presentarla, es su silencio. Amama a lo largo del desarrollo del argumento no pronuncia ni una sola palabra. Las posibles interpretaciones exigen una explicación más amplia.

Por un lado, su pasividad y actitud silenciosa podría asociarse con la posición que actualmente ocupa dentro de la familia entendida como "grupo doméstico". El "grupo doméstico" es un concepto derivado de la visión tradicional de la familia vasca que significa un conjunto de personas relacionadas entre sí por el hecho de cohabitar y trabajar juntas en el caserío, siendo de este modo también una unidad económica. Los lazos de sangre no eran necesarios para considerar alguien un familiar, aunque normalmente los grupos domésticos en gran medida se formaban de personas vinculadas por consanguinidad. Según este concepto, la familia se compone de una "pareja activa", o sea, un matrimonio que lidera el caserío (organiza el trabajo de sus miembros, toma las decisiones clave para su funcionamiento y gestiona los bienes), sus hijos y, eventualmente, otras personas que cohabitan y trabajan en el caserío $^{18}$ y por último, una "pareja retirada": los abuelos, los cuales al ceder el liderazgo tienen que aceptar las formas de administrar y ordenar el baserri por los nuevos amos (Homobono 1991: 102-105). La película parece seguir estas reglas de correspondencia del poder. Ama$m a$, como la antigua señora de la casa, la que después de trasferir el caserío a su heredero, en este caso su hijo y el padre de Amaia, obtuvo el estatus de "retirada" y por consiguiente deja de influir realmente en la vida de la familia.

Sin embargo, su silencio parece tan manifestativo que trasciende esta sencilla interpretación. Vamos a referirnos a la única escena con la participación de la abuela que se desarrolla en la ciudad. En la secuencia Amaia lleva a su abuela a la galería de arte en la que va a exponer sus obras. Mientras habla sobre los preparativos con el conservador de la futura exposición, amama la espera sentada delante de una pintura abstracta ${ }^{19}$, mirándola fijamente. Al final de la secuencia Amaia se acerca a ella y la presenta al conservador. El hombre

18 Entre ellos podían encontrarse por ejemplo hermanos, parientes o criados, pero en el caso de adultos todos solteros. Si alguien no era el heredero o la heredera del baserri pero aspiraba a contraer matrimonio tenía que abandonar la casa después de casarse (Homobono 1991: 102-104).

19 Se trata de un óleo de Joxan Iza, un artista que en su arte se enfoca en el tema del ser humano y la ciudad. La elección de esta obra concuerda con el motivo del enfrentamiento entre la ciudad y el caserío representado en la película. 
viendo su mirada intensa enfocada en la pintura le pregunta si le gusta la obra. Antes de que pueda sonar la respuesta, hay un corte de montaje ${ }^{20}$.

Quitarle la voz en este contexto y de modo tan llamativo nos hace percibir el silencio como su atributo principal. De esta forma, aunque es el personaje central de la acción y una simbolización de la diosa Mari, resulta privada de posibilidad de cualquier expresión. Su mirada tan intensa, aunque le provoca mucha impresión en el espectador, no tiene suficiente fuerza para accionar a ningún personaje dentro de la ficción. Es una representación muda e inmóvil. Hipnótica, inquietante y atrayente, pero carente de existencia personal. Parece un símbolo o emblema potente pero en ningún caso una persona de carne y hueso. Amama encarna un ideal simbólico-cultural, la condición idealizada de la mujer que no refleja su situación real. Por eso, parece justificado interpretar este personaje como una manifestación del mito del matriarcado.

El silencio de amama y de la madre contrasta con la voz de Amaia. Ella es la narradora en el filme, y la única persona que cuenta su propia historia y las historias de los demás. En varias ocasiones junto a su voz aparece la voz de su padre. La dinámica entre los dos se podría caracterizar con los versos del poema que inspiró la trama: "Su voz era capaz de hacer callar / a cualquiera. / Sólo su hija se atrevía con él" (Uribe 2003). Aunque los hermanos de Amaia son capaces de actuar contra la voluntad del padre, ella es la única de la familia que se contraria a él de forma abierta y que verbaliza su protesta. La protagonista quiere contar su historia con su propia voz, no teme enfrentamientos. Su postura esencialmente activa se manifiesta asimismo en la escena en la que pinta los árboles que corresponden a sus hermanos y a ella misma, de todos los colores. Es un acto simbólico de liberación del destino asignado por amama, lo que sugiere una rebelión también contra ella. Sin embargo es una rebeldía paradójica, ya que se inscribe en su condición de rebelde impuesta de modo arbitrario. Además, amama no deja de ser el tema principal del arte de su nieta.

Entre los elementos auditivos de gran importancia se encuentran los susurros que se oyen tanto en el bosque con los árboles pintados, como en las grabaciones de Amaia. Por la forma sugestiva de incorporarlos en el filme se pueden reconocer como las voces de espíritus o antepasados. De este modo se convierten en uno de los recursos de construir la imagen del bosque como un espacio especial, relacionado con la dimensión espiritual-mitológica que concuerda con la visión tradicional de este tipo de espacio (Homobono 1991: 110). Es un lugar eterno que asegura el contacto con el pasado y por esta razón se convierte en una de las mayores inspiraciones del arte de Amaia. Otro contexto espacial de gran importancia es el baserri, que también alude a las relaciones con el pasado y la tradición, pero -como ya hemos indicado- de una manera distinta. Es más bien una representación del orden social, determinado por los ciclos del trabajo y el poder paterno. Sin embargo, mientras que los valores representados por el baserri están a punto de desaparecer, los representados por el bosque y amama perdurarán gracias al arte de Amaia.

En varias obras se observan las caras de Amaia y su abuela puestas una sobre la otra o las mitades de sus caras unidas en una imagen. De esta manera la artista establece un paralelismo entre amama y ella misma. Cuando amama muere, el vínculo al neolítico se pierde. El arte de Amaia continúa, convirtiéndose en el canal de comunicación con la "esencia mítica". Desde esta perspectiva la actividad creativa de la protagonista principal se asocia con la función tradicional de la mujer como la que transmite los valores culturales (Valle Murga 1983) y, al mismo tiempo, constituye una idea del misticismo femenino basado en la relación especial entre la mujer y la diosa Mari que según algunas interpretaciones formaba parte de la visión del mundo incluida en la mitología vasca: "hay correlación fundamental entre la diosa Mari, que es la personificación de la Tierra y su Alma Madre, y la Señora de casa, la cual es la personificación de la casa y su alma madre: la Etxekoandre" (Ortiz Osés 2007: 53). Esta construcción simbólica se considera la base del "matriarcado vasco". Sin embargo, dentro del mundo de la ficción fílmica este vínculo simbólico no implica ningún tipo de poder real de las protagonistas. Al fin y al cabo ni poderes simbólicos ni espirituales permiten abolir las desigualdades.

20 En el escenario en esta secuencia había también una escena que finalmente no se utilizó en la película, en la que una pareja de visitantes mira la abuela como si ella misma fuera un objeto expuesto. Aunque la escena se cortó de la versión final, parece confirmar la interpretación del personaje que se expone en el siguiente párrafo. 


\section{Conclusiones}

Resumiendo, las interpretaciones de la condición femenina en las obras fílmicas comentadas resultan ambiguas. Amama resalta una discrepancia entre la situación idealizada y la real de la mujer, pero, en contraste con la imagen propuesta en Matria, carece de la crítica abiertamente expresada: su distanciamiento consiste más bien en el uso de ciertos recursos formales que aportan significados adicionales por lo cual el aspecto crítico aquí presente se debe a lo implícitamente incorporado en la realidad fílmica. Metaforizando la realidad fuera de la pantalla, hace visible lo que en el nivel de lo irreflexivo y cotidiano queda transparente. El valor crítico de esta película no es inmanente, sino más bien nace en el contacto con el espectador-interpretador.

Matria, en este sentido es mucho más explícita. El objetivo de denuncia social se subraya a través de la estética realmente cruda, cercana a la que solemos asociar con el cine de corte documental. En Matria se formula un mensaje sobre la vida de las mujeres gallegas como explotadas en los entornos tradicionales tanto familiares como laborales. En esta imagen de realidad patriarcal, ni siquiera se necesita presencia física de los hombres para que el sistema se mantenga. La estabilidad de las relaciones de poder encontramos asimismo en Amama. Aunque la protagonista principal sea una mujer rebelde y aunque las formas de vivir que considera anacrónicas estén muriendo, el referente para los miembros de la familia y para ella misma sigue siendo el padre. En pocas palabras, mientras que, en caso de Ama$m a$, las maneras de vida desaparecen, y en el de Matria, las generaciones se suceden, la mentalidad y los roles de género no cambian rápidamente.
Perteneciendo a generaciones diferentes, los dos cineastas emprenden el tema de la posición de la mujer en la sociedad desde dos perspectivas y dos tipos de sensibilidad divergentes, abordando las creencias arraigadas profundamente que resultan discriminatorias para sus protagonistas. El interés por el tema en la cinematografía gallega y vasca contemporánea muestra la vitalidad del mito pese a los cambios sociales y, al mismo tiempo, demuestra lo lento que es el proceso de la emancipación de la mujer.

Pese a unas diferencias evidentes e importantes, hay una serie de factores que permiten hablar de una visión similar del 'mito del matriarcado'. Primero, aunque los filmes presenten visiones discordes, la intención directa de los realizadores de ambas producciones fue dar homenaje a la figura femenina, en el caso de Amama por su importancia simbólica y, en el caso de Matria, por el vínculo personal y afectivo. Segundo, en lo formal, ambas obras se caracterizan por una estructura narrativa organizada en torno a tres elementos (tres espacios en el caso de Matria y tres colores y tres niveles de realidad en el caso de Amama) y la diferenciación clara en las tomas dependiendo de cada elemento. Tanto en Matria como en Amama hay tres personajes femeninos de tres generaciones distintas aunque el enfoque difiere y el protagonismo de cada una de ellas no es proporcionado. En ambos casos, las mujeres están atrapadas por el sistema socio-cultural persistente y, pese a los brotes de rebeldía, no pueden librarse de los condicionantes patriarcales. Asimismo, tanto en Matria como en Amama se aborda el problema de la alienación y la incomunicación de la mujer. Igualmente, en ambas producciones es la familia el patrón principal que parece ser el decisivo en el mantenimiento del estatus quo.

\section{Referencias bibliográficas}

Ahmed, Sara (2018): Vivir una vida feminista. Barcelona: Edicions Bellaterra.

Aranzadi, Juan (2000): Milenarismo vasco. Edad de oro, etnia y nativismo. Madrid: Santillana de Ediciones. (2001): "Raza, linaje, familia y casa-solar en el País Vasco", Hispania 209, pp. 879-906, http://

hispania.revistas.csic.es/index.php/hispania/article/view/281/282.

Barandiarán, José Miguel de (2014): Mitología vasca. Donostia-San Sebastián: Txertoa.

Barsam, Richard y Dave Monaham (2019): Looking at Movies. An Introduction to Film. New York/London: W. W. Norton \& Company.

Blanco García, Carmen (1996): El contradiscurso de las mujeres. Vigo: Nigra.

Bullen, Margaret (2000): Basque gender studies. Reno: Center for Basque Studies, University of Nevada. Butler, Alison (2002): Women's Cinema. The Contested Screen. London / New York: Wallflower.

Butler, Judith (2014): "Vida precaria, vulnerabilidad y ética de cohabitación", en B. Saez Tjafuerce (ed.), Cuerpo, memoria y representación. Adriana Cavarero y Judith Butler en diálogo. Barcelona: Icaria, pp. 40-47. 
Caro Baroja, Julio (1998): Ser o no ser vasco. Madrid: Espasa.

Castro, Olga y María Reimóndez (2013): Feminismos. Vigo: Xerais.

CRTVG (2018): "Matria, de Álvaro Gago, gran premio do xurado de Sundance”, 24/01/2018, http://www. crtvg.es/informativos/matria-de-lvaro-gago-gran-premio-do-xurado-en-sundance-3620299 [consulta: $13 / 12 / 2019]$.

Dragovič, Nono (2012): Poetyka reżyserii filmowej. Toruń: Wyd. Adam Marszałek.

Encyclopaedia Britannica, https://www.britannica.com/biography/bell-hooks [consulta: 13/12/2019].

Fente, Elvira (2010): Parir a liberdade. O movemento feminista en Galicia. Santiago de Compostela: Alvarellos.

Gago, Álvaro (2017): Matria. Sombriza Films\&Ringo Media.

(2017): "Directing: Matria", https://www.alvarogago.com/matria [consulta:13/12/2019].

(2018): “MATRIA Tra-la camara con 'Matriarcas' de GuadiGalego”, YouTube 06/04/2017, https:// www.youtube.com/watch?v=dR6Yvr7HHok [consulta: 13/12/2019].

García Negro, María do Carme y Yolanda N. Zotes Tarrío (2006): "El trabajo de las mujeres en el sector pesquero gallego: análisis de los problemas relacionados con su tratamiento estadístico", Revista Galega de Economía 15, pp. 1-25, http://www.usc.es/econo/RGE/Vol15 1/castelan/art6c.pdf.

González Fernández, Helena (2009): Género y Nación. La construcción de un espacio literario. Barcelona: Icaria.

Gubern, Román (2004): Patologías de la Imagen. Barcelona: Anagrama.

Homobono, José Ignacio (1991): “Ámbitos culturales, sociabilidad y grupo doméstico en el País Vasco”, Revista de antropología social 0, pp. 83-114.

hooks, bell (2003): "The Oppositional Gaze: Black Female Spectators", en A. Jones (ed.), The Feminism and Visual Culture Reader. London/New York: Routledge, pp. 94-105.

Huete, Cristina (2018): "Retrato de Galicia, donde las mujeres tampoco mandan", El País 02/02/2018, https://elpais.com/cultura/2018/01/31/actualidad/1517408272_817446.html [consulta: 13/12/2019].

Kuśmierczyk, Seweryn (2014): "Analiza antropologiczno-morfologiczna dzieła filmowego", en S. Kuśmierczyk (ed.), Wyprawa bohatera w polskim filmie fabularnym. Warszawa: Czuły Barbarzyńca, pp. 13-34.

(2015): "Wprowadzenie. Analiza antropologiczno-morfologiczna dzieła filmowego jako praktyka filmoznawcza", en S. Kuśmierczyk (ed.), Antropologia postaci w dziele filmowym. Warszawa: Czuły Barbarzyńca, pp. 11-29.

Martínez, Bea (2018): "Entrevista al cineasta gallego Álvaro Gago creador de Matria. Parte I", Beamos Producción 14/07/2018, http://beamos.es/entrevista-al-cineasta-gallego-alvaro-gago-creador-de-matriaparte-i/ [consulta: 13/12/2019].

Nichols, Bill (2010): Engaging Cinema. An Introduction to Film Studies. New York/London: W. W. Norton \& Company.

Ortiz-Osés, Andrés (1981): El matriarcalismo vasco. Reinterpretación de la cultura vasca. Bilbao: Universidad de Deusto.

(2007): Los mitos vascos: aproximación hermenéutica. Bilbao: Universidad de Deusto.

Paszkiewicz, Katarzyna (2017): Rehacer los géneros. Mujeres cineastas dentro y fuera de Hollywood. Barcelona: Icaria.

Pena Boquete, Yolanda (2009): O emprego feminino en Galiza: Os cambios pendentes. Tese de doutoramento. Santiago de Compostela: Universidade de Santiago de Compostela, https://dialnet.unirioja.es/ servlet/tesis?codigo=107600 [consulta: 13/12/2019].

Romero Suárez, Brais (2015): “Idioma e Identidad en el Novo Cinema Galego", Fonseca. Journal of Communication 11, pp. 9-31, https://revistas.usal.es/index.php/2172-9077/article/view/13433/13711.

Sabadell Nieto, Joana (2011): Desbordamientos. Transformaciones culturales y políticas de las mujeres. Barcelona: Icaria.

Suárez, Pablo (2014): “O 'Novo Cinema Galego'. Galiza na senda de vangarda”, Madrygal. Revista de Estudios Gallegos 17, pp. 123-130, DOI: https://doi.org/10.5209/rev_MADR.2014.v17.45743.

Uribe Kirmen (2003): “Maite zaitut, ez”, https://www.lyrikline.org/es/poemas/maite-zaitut-ez-3079 [consulta: 13/12/2019].

Valle Murga, María Teresa del (1983): "La mujer vasca a través del análisis del espacio: utilización y significado", Lurralde: Investigación y espacio 6, pp. 251-270.

(1985): Mujer vasca. Imagen y realidad. Barcelona: Anthropos.

Zecchi, Barbara (2014): Desenfocadas. Cineastas españolas y discursos de género. Barcelona: Icaria. 